\title{
BIOSYNTHESIS OF FUNCTIONALIZED GOLD NANOPARTICLES BY USING METHYL COMMATE C IN Scoparia dulcis LEAF EXTRACT AS REDUCING AGENT
}

\author{
J. Mary Joselin, V. Ganesh Kumar*, T. Selvaraj, K. Govindaraju \\ and V. Karthick \\ Nanoscience Division, Centre for Ocean Research, Sathyabama Institute of Science and \\ Technology, Chennai, Tamilnadu, India-600 119. \\ *E-mail: ganeshkumar@sathyabama.ac.in
}

\begin{abstract}
Biosynthesis of nanoparticles is studied extensively for its biocompatibility and its environmentally friendly nature. In the present study, the synthesis of gold nanoparticles is carried out using Scoparia dulcis aqueous leaf extract. The synthesis of gold nanoparticles is achieved at room temperature using aqueous leaf extract of Scoparia dulcis without the addition of an external agent. The color change was observed from light brown to ruby red indicating the formation of gold nanoparticles. The surface plasmon resonance band appeared at $542 \mathrm{~nm}$ in Ultra Violet-visible spectroscopy. In Fourier Transform Infrared spectroscopy the functional groups responsible for the reduction of chloroauric acid have been identified and in Transmission Electron Microscopy revealed that the gold nanoparticles were of 20-27 nm in size. Gas Chromatography-Mass Spectroscopy analysis and Nuclear Magnetic Resonance spectroscopy were used to assess the structure of the reducing agent.
\end{abstract}

Keywords: Spectroscopy, Nanomaterials, Scoparia dulcis, Gold nanoparticles, Methyl commate C

(C) RASĀYAN. All rights reserved

\section{INTRODUCTION}

Plant-derived products are present in most pharmaceutical preparations that many are currently recommended by medical practitioners as they are part of the health-care system. Relating phytochemistry of plants with nanomaterials will be helpful in developing more effective drugs for various diseases. Recently, many nanomaterials, such as nanoparticles, nanowire and nanodisks have been prepared using various synthetic protocols. ${ }^{1}$ Nanoparticles are used to combat several diseases as medicinal agents in therapeutic applications. ${ }^{2,3}$ Metallic gold nanoparticles have been employed in many fields, such as catalysts for numerous environmental progressions, antimicrobial agents against a wide range of microorganisms. ${ }^{4}$ Hence, the controlled fabrication of nanoparticles in terms of size and shape can augment in specific to drug delivery ${ }^{5}$ and catalytic applications. ${ }^{6}$ Conventionally, nanoparticles are synthesized by different physical and chemical methods and some disadvantages of these methods are expensive and also involve the use of toxic and hazardous chemicals. ${ }^{7}$ Therefore, biological methods like using microorganisms ${ }^{9}$, enzymes ${ }^{10}$ are being been proposed as possible eco-friendly alternatives for the synthesis of nanoparticles. The potential plant extracts for the synthesis of nanoparticles is gaining priority in recent terms for their medicinal value. The use of plant materials for the green synthesis of nanoparticles has evolved in the last decade. Plants contain certain bioactive compounds like flavonoids, phenols, citric acid, ascorbic acid, polyphenolic, terpenes, alkaloids and reductase which act as reducing agents. Plant and seaweeds involved in the synthesis of gold nanoparticles is a very promising area of nanomaterials because the bioorganic compounds act as both reducing and capping agents. ${ }^{8,10}$ It is well established that plants and its phytochemicals are used in various biomedical applications. ${ }^{11,12}$

Plants materials having property to cure various disorders in human beings or in animals with lower or no adverse effects can be termed as medicinal plants. $S$. dulcis plants have been traditionally used as 
RASĀYAN J. Chem.

Vol. 13 | No. 1 |188 - 194| January - March | 2020

remedies for diabetes mellitus in India both as fresh and dried form. ${ }^{13}$ It is used in curing ailments such as fever, diarrhea, ulcer, cancer, wounds, skin rash, cough and tuberculosis. ${ }^{13}$ Considering the potential applications into account, the present work has been focused on synthesizing gold nanoparticles using Scoparia dulcis extract without the addition of any external agent. In addition, the reducing agent present in the extract was also deducted with the help of mass and nuclear magnetic resonance spectroscopy.

\section{EXPERIMENTAL}

\section{Preparation of Plant Extract}

Freshly collected leaves of Scoparia dulcis were washed properly with tap water followed by Milli-Q water to remove any contaminants. $5 \mathrm{~g}$ of leaves were boiled separately with $100 \mathrm{~mL}$ of deionised water at $80{ }^{\circ} \mathrm{C}$ for $10 \mathrm{~min}$. The extract obtained was filtered through Whatman No.1 filter and kept at $4{ }^{\circ} \mathrm{C}$ until used for further study.

\section{Synthesis of Gold Nanoparticles}

An aqueous solution of leaf extract (Scoparia dulcis) from various concentrations were prepared separately with each concentration of the leaf extract was added $1 \mathrm{mM} \mathrm{HAuCl}_{4}$ prepared solution. The synthesis of gold nanoparticles was carried out with $60 \mathrm{~mL}$ of $1 \mathrm{mM} \mathrm{HAuCl}_{4}$ solution as mixed with 40 $\mathrm{mL}$ of Scoparia dulcis aqueous leaf extracts, the reaction was kept at room temperature. After $60 \mathrm{~min}$, the color of the solution (leaf extract $+\mathrm{HAuCl}_{4}^{+}$) changed from light yellow to ruby red color indicating the formation of gold nanoparticles. The resulting colloidal solution of gold nanoparticles was analyzed using various spectroscopic and microscopic analyses.

\section{Characterization of the Scoparia dulcis Synthesized Gold Nanoparticles}

The indication of the color change from light yellow to ruby-red color indicated the formation of the gold nanoparticles. The excitation spectrum of the synthesized gold nanoparticles and has been measured by UV-Visible spectrophotometer (Shimadzu UV-1800) in the wavelength range of 250-800 nm. FT-IR spectroscopy was used to characterize the functional groups involved in the reduction of gold ions to nanoparticles was achieved by FT-IR (Fourier Transform Infrared) Shimadzu spectrophotometer IRAffinity-1s, Japan. FT-IR analysis was carried out for both plant extract and gold nanoparticles to identify the possible biomass responsible for the reduction and capping agent molecules. Transmission Electron microscopy (TEM) (JEOL 3010 instrument with a UHR polepiece) study reveals that the shape and size of the nanoparticles and were recorded by placing a drop of the suspension on carbon-coated grid and allowing water to evaporate.

\section{GC-MS and NMR Analysis}

GC-MS was used to assess the biomolecules present on the surface of the gold nanoparticles. Gold nanoparticles synthesized using plant aqueous extracts of Scoparia dulcis was taken for GC-MS analysis using GC-MS QP2010 Ultra (Shimadzu). GC program: initial temperature: $80^{\circ} \mathrm{C}$ (1min hold) $>$ Further increasing $4^{\circ} \mathrm{C}>200^{\circ} \mathrm{C}>10^{\circ} \mathrm{C} 280^{\circ} \mathrm{C}(4 \mathrm{~min}$ hold $)$, total program: $43.0 \mathrm{~min}$. MS program: Ion Source Temp: $250^{\circ} \mathrm{C}$ Interface temp: $280^{\circ} \mathrm{C}$, Solvent cut time:3min. Column Name: Rxi-5sil MS, Length : 30 meter, Thickness $\quad: 0.25 \mu \mathrm{m}$, Diameter: $0.25 \mathrm{~mm}$. Gas Flow: Carrier gas: helium $99.999 \%$ purity, Column flow: $1.10 \mathrm{ml} / \mathrm{min}$, Purge flow: $3 \mathrm{ml} / \mathrm{min}$. To ascertain, ${ }^{1} \mathrm{H}$ and ${ }^{13} \mathrm{C}$ NMR spectra were measured by mixing with Dimethyl sulfoxide (DMSO-d6) and recorded at $800 \mathrm{MHz}$ Bruker Spectrometer (Avance III, US2).

\section{Scoparia dulcis Synthesized Gold Nanoparticles}

\section{RESULTS AND DISCUSSION}

Gold nanoparticles have many applications in the biomedical field. Improving delivery of anticancer agents to tumors using nanoparticles is one of the most promising research areas in the field of nanotechnology. ${ }^{14,15}$ The treatment of an aqueous solution of chloroauric acid with biomass of Scoparia dulcis led to the formation of gold nanoparticles. Gold nanoparticles exhibit plasmon absorption bands that depend on their size and shape. The absorption maxima in the range $520 \mathrm{~nm}$ indicates the formation of the gold nanoparticles which may be due to excitation of Surface Plasma Resonance (SPR). UV-vis spectra of aqueous leaf extract Scoparia dulcis (Fig.-1). The UV-vis spectra of the gold nanoparticles 
RASĀYAN J. Chem.

Vol. 13 | No. 1 |188 - 194| January - March | 2020

synthesized using plant leaf aqueous extracts of Scoparia dulcis showed peak as $542 \mathrm{~nm}$ (Fig.-2). ${ }^{16}$ Formation of gold nanoparticles was monitored with respect to different time intervals under UV-visible spectroscopy. Synthesis of gold nanoparticles increased with an increase in time of incubation with $\mathrm{HAuCl}_{4}$ solution along with aqueous leaf extract of Scoparia dulcis. The leaf extract of Scoparia dulcis significantly reduced the formation of $\mathrm{HAuCl}_{4}$ into gold nanoparticles, the secondary metabolites present in the extract act as a reducing and a capping agent for gold nanoparticles synthesis. The observed symmetric nature of the surface plasma resonance indicates the formation of spherical nanoparticles. It was further confirmed by the TEM images.

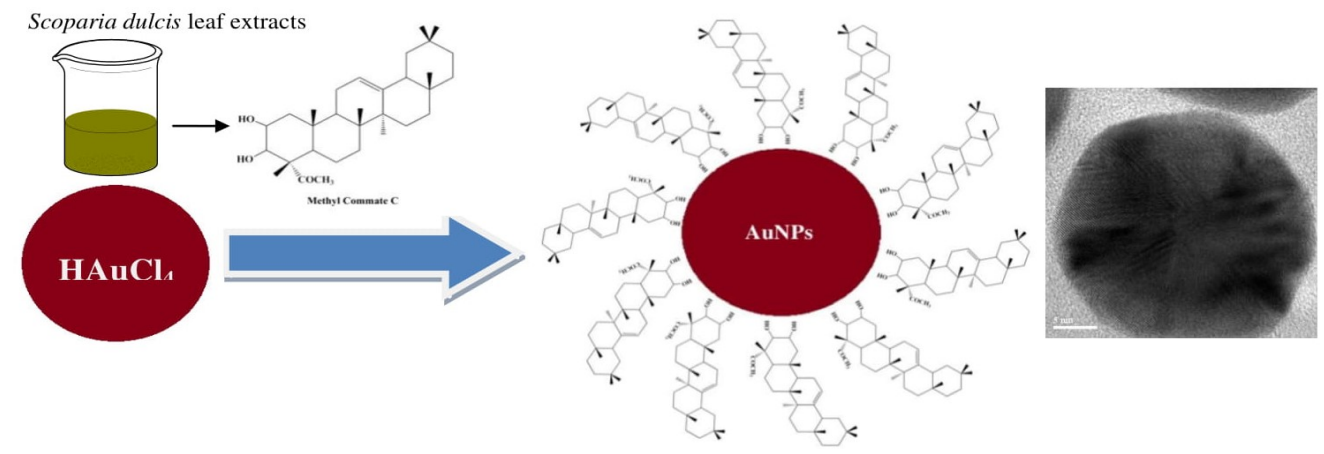

Fig.-1: Schematic representation of the Synthesis of AuNPs synthesized using Methyl Commate C in Plant Aqueous Extracts of Scoparia dulcis

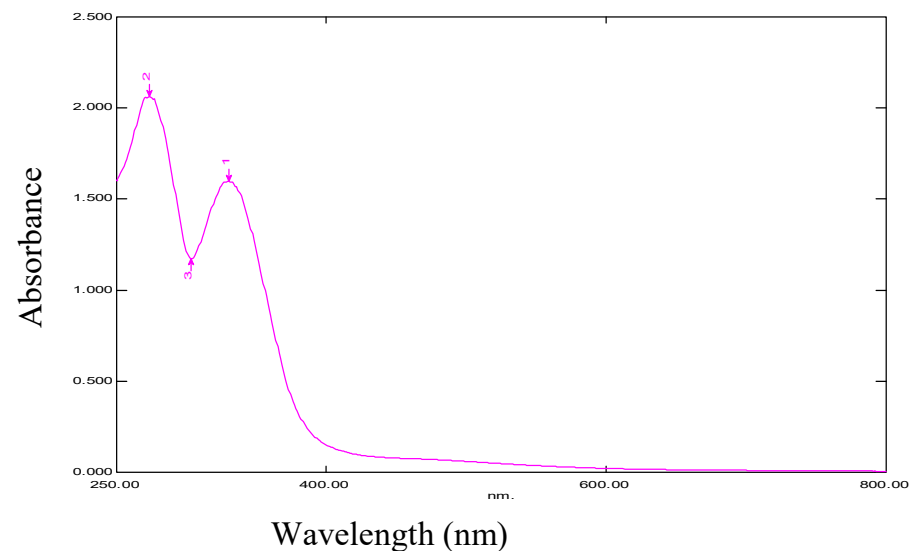

Fig.-2: UV-vis Spectra of Scoparia dulcis Plant Leaf Aqueous Extracts

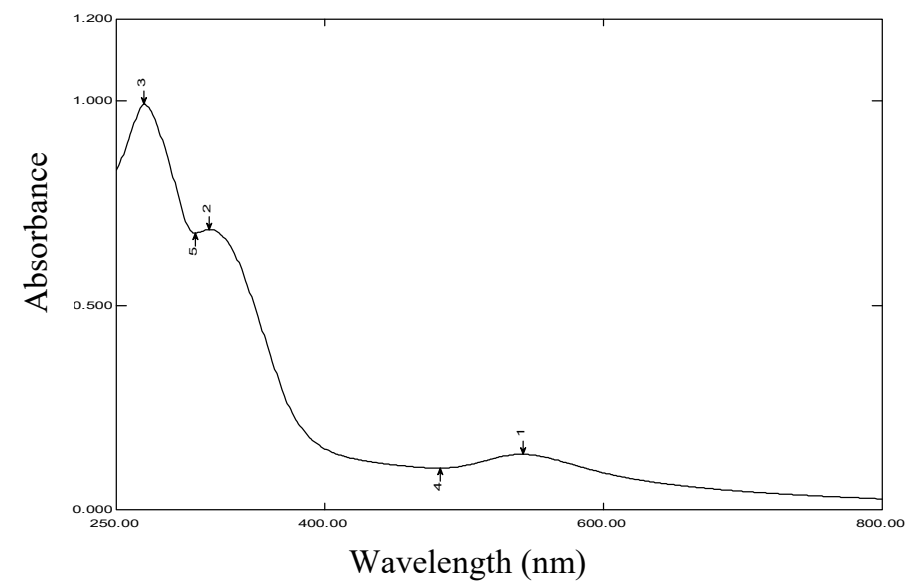

Fig.-3: UV-Vis Spectra of Gold Nanoparticles synthesized using Plant Leaf Aqueous Extracts of Scoparia dulcis 
RASĀYAN J. Chem.

Vol. 13 | No. 1 | 188 - 194| January - March | 2020

\section{FTIR Analysis}

FTIR analysis of Scoparia dulcis aqueous leaf extract and Scoparia dulcis aqueous leaf extract synthesized gold nanoparticles were studied to identify possible functional groups involved in the reduction and stabilization of gold ions into gold nanoparticles. The FTIR spectra of Scoparia dulcis leaf extract indicated various functional groups present at different positions. The corresponding absorption peak at region 3400, 2939, 2389, $21181633,1389,1250$ and $1179 \mathrm{~cm}^{-1}$ (Fig.-3), while the 3373, 2919, $1660,1512,1413,1383,1326$ and $1237 \mathrm{~cm}^{-1}$ for the synthesized gold nanoparticles can be observed in Fig.-3 and 4. The results revealed that the absorption peak at region 3400 and $2939 \mathrm{~cm}^{-1}$ was shifted and appearance of the new broad absorption peak at 3373 and $2919 \mathrm{~cm}^{-1}$ was seen corresponds to -O-H Stretching, H-bonded alcohols, and phenols. Whereas the disappearance peaks at 2389 and $2118 \mathrm{~cm}^{-1}$ were observed which was responsible for the reduction and capping of gold nanoparticles ${ }^{17,18}$

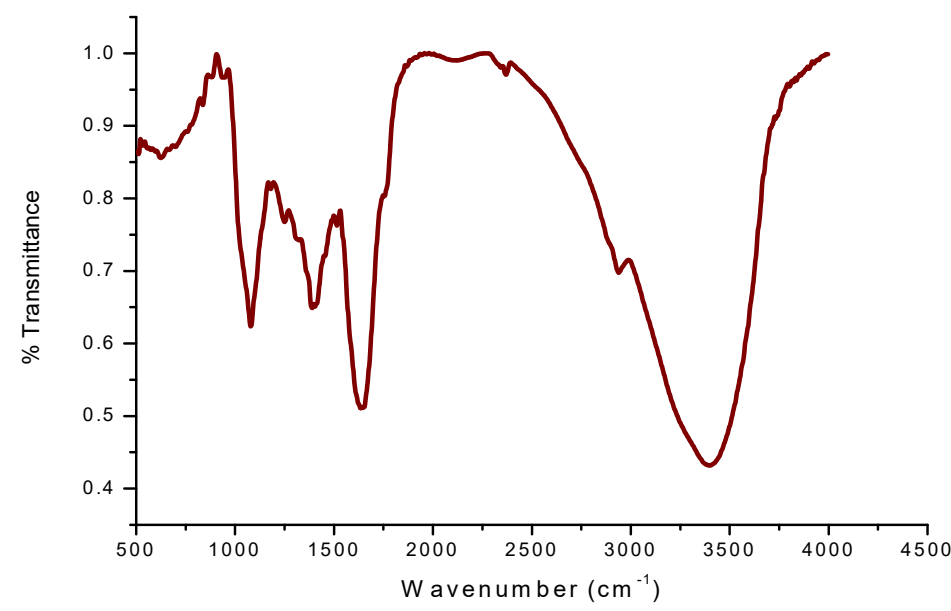

Fig.-4: FTIR Analysis of Scoparia dulcis Plant Aqueous Extracts

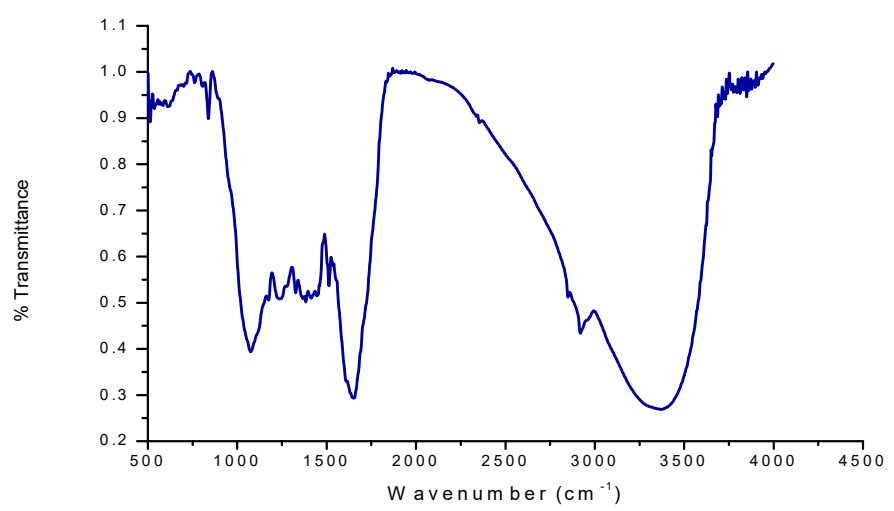

Fig.-5: FTIR Analysis of Gold Nanoparticles synthesized using Plant Aqueous Extracts of Scoparia dulcis

\section{Transmission Electron Microscope (TEM) Analysis}

Transmission electron microscopy was used to investigate the shape and size of the gold nanoparticles synthesized using aqueous leaf extract of Scoparia dulcis. The sample preparation for TEM characterization involves placing a drop of solution on a carbon-coated copper grip which was dried at room temperature, while the residual solution was removed with the blotting paper. It is clear from highresolution TEM image analysis to observed shape and size of the nanoparticles diameter ranging from 20$27 \mathrm{~nm} .{ }^{17}$ Figure-5 illustrates the TEM image of gold nanoparticles synthesized using plant aqueous extracts of Scoparia dulcis on depicts the spherical shaped and hexagonal shape were observed. ${ }^{20,21}$ This 
RASĀYAN J. Chem.

Vol. 13 | No. 1 | 188 - 194| January - March | 2020

indicated that the biomolecules of plant Scoparia dulcis were effectively involved in the synthesis and controlled the formation of gold nanoparticles. Gold nanoparticles with thin, smooth ends on the exterior of the nanoparticles were seen in the TEM micrographs.
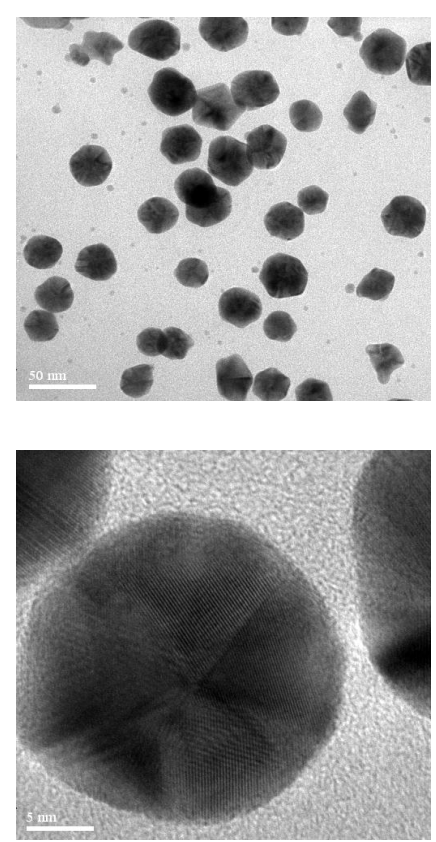
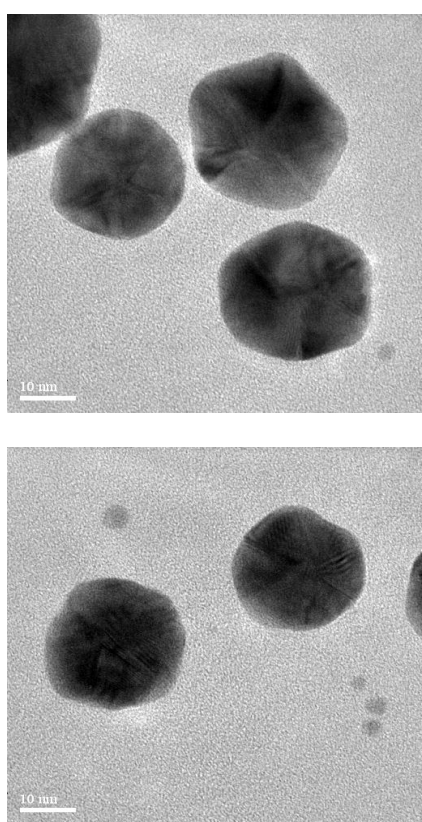

Fig.-6: TEM Images of Gold Nanoparticles synthesized using Leaf Extract of Scoparia dulcis

\section{GC-MS and NMR Analysis}

GC-MS was employed to assess the biomolecules present on the surface of the gold nanoparticles and helped in the stabilization of gold nanoparticles. Five different types of peaks were observed in the chromatogram and the percentage of Methyl Commate $\mathrm{C}$ observed was $60.58 \%$ (Fig.-6). The GC-MS retention time (RT) and percentage peak of the compounds were demonstrated in table- 1 . In the present analysis, the compounds were confirmed by matching obtained spectral data with Wiley/ NIST/EPA/NIH mass spectral library (NIST 11). ${ }^{22}$

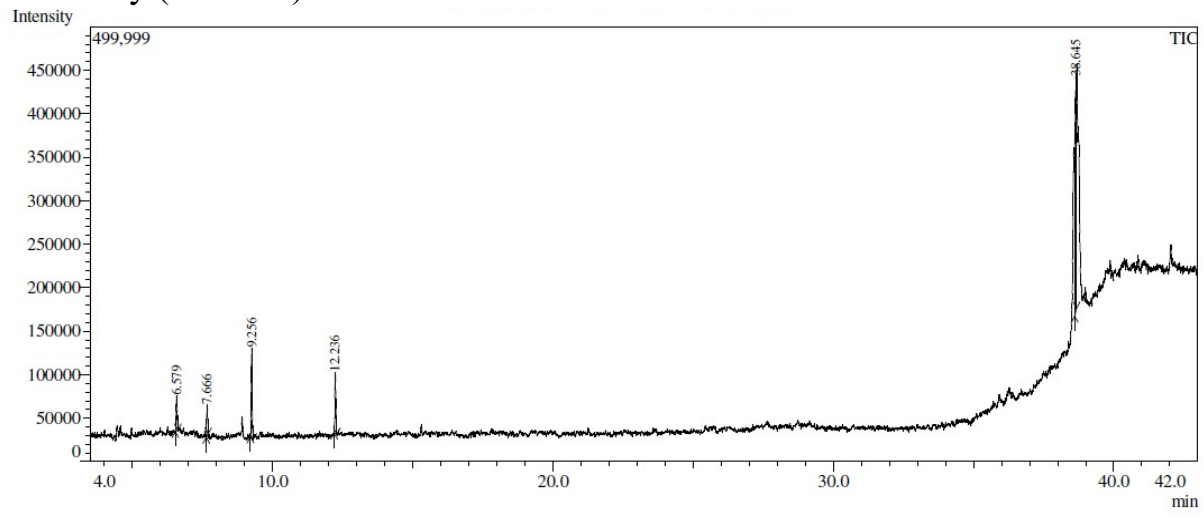

Fig.-7: GC-MS Chromatogram of Gold Nanoparticles synthesized using Leaf Extract of Scoparia Dulcis

Nuclear magnetic resonance was used to ascertain the caped molecule on the surface of gold nanoparticles. Figure-8 (A) and (B) represent the ${ }^{1} \mathrm{H}$ and ${ }^{13} \mathrm{C}$ NMR assignments for the compound methyl commate $\mathrm{C}$ taken at the retention time 38.64 . The peaks found between $140 \mathrm{ppm}$ and $160 \mathrm{ppm}$ indicates the aromatic resonances of the compound with slight impurities. From the assignments, it is evident that 
RASĀYAN J. Chem.

Vol. 13 | No. 1 |188 - 194| January - March | 2020

the compound obtained in the mass spectrometry matches with the NMR signals confirms the presence of methyl commate $\mathrm{C}$ on the gold nanoparticles. A schematic diagram represents the Methyl Commate $\mathrm{C}$ present in aqueous leaf extracts of Scoparia dulcis combines with gold ions to form the complex (Fig.-8). This will be helpful for further application studies to prepare methyl commate $\mathrm{C}$ reduced gold nanoparticles for potential biomedical applications. Based on the study it could be inferred that medicinal plants the subject of human curiosity and to utilize in an effective way in nanoparticle synthesis.

Table-1: Chemical Constituents Present in the Gold Nanoparticles synthesized using

Leaf Extract of Scoparia Dulcis using GC-MS Analysis

\begin{tabular}{|r|r|r|r|l|}
\multicolumn{5}{|c|}{ Peak Report TIC } \\
\hline Peak\# & R.Time & Area & Area\% & Name \\
\hline 1 & 6.579 & 83975 & 5.66 & Undecane \\
\hline 2 & 7.666 & 75427 & 5.09 & 2,6-DIMETHYL-6-NITRO-2-HEPTEN-4-O \\
\hline 3 & 9.256 & 251203 & 16.94 & Dodecane \\
\hline 4 & 12.236 & 174051 & 11.74 & Tridecane \\
\hline 5 & 38.645 & 898488 & 60.58 & METHYL COMMATE C \\
\hline & & 1483144 & 100.00 & \\
\hline
\end{tabular}
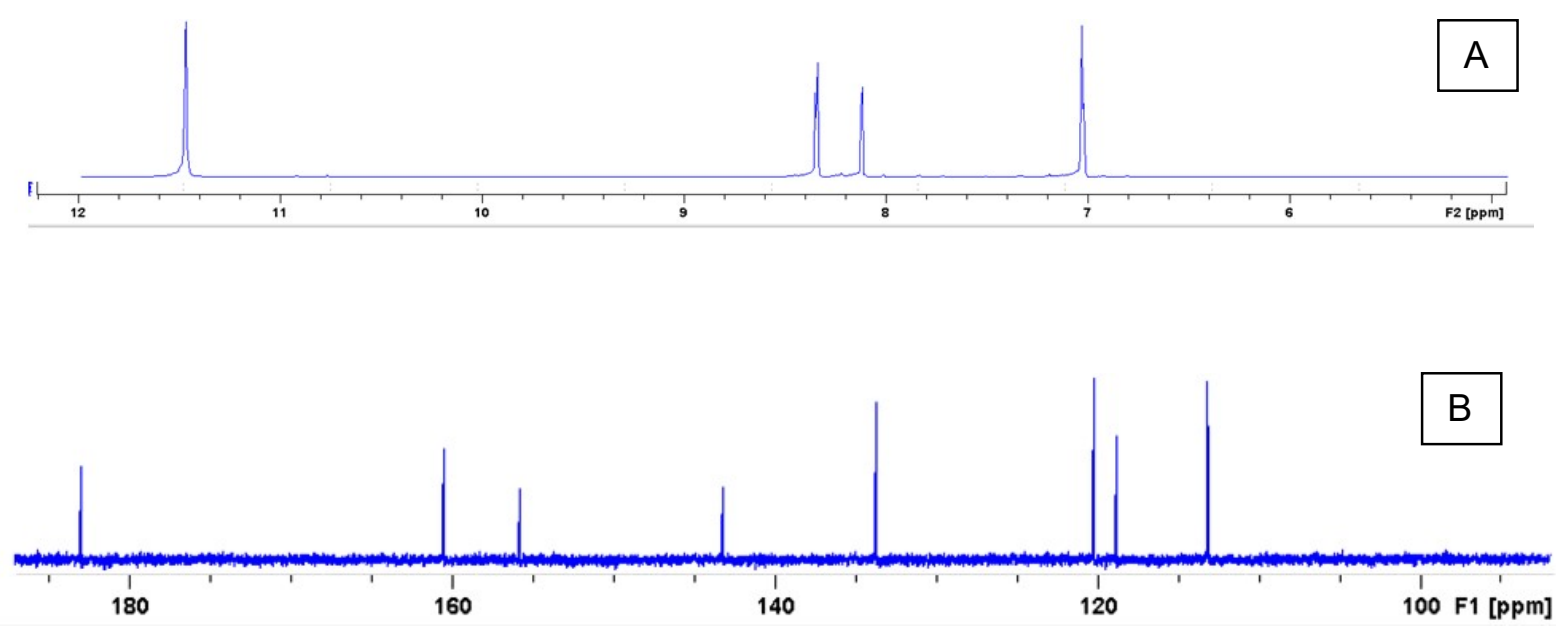

Fig.-8: ${ }^{1} \mathrm{H}(\mathrm{A})$ and ${ }^{13} \mathrm{C}(\mathrm{B})$ NMR Spectra of Quercetin measured in 100\% DMSO-d6 at A Temperature of $300 \mathrm{~K}$

\section{CONCLUSION}

Biosynthesis of gold nanoparticles using a simple green method has been achieved and the capping procedure could be useful for potent biomedical applications. Spectroscopic and microscopic analyses inferred that the gold nanoparticles are spherical and hexagonal in shape. The reducing agent in the plant was identified using GC-MS and NMR analysis out and the stabilizing compound was found to be methyl commate $\mathrm{C}$ a well-known compound of biomedical applications.

\section{ACKNOWLEDGMENT}

We thank the management of Sathyabama Institute of Science and Technology, Chennai, for its strong support in research activities.

\section{REFERENCES}

1. M.R. Rashidian Vaziri and F. Hajiesmaeilbaigi, Optik - International Journal for Light and Electron Optics, 126(14), 1348(2015), DOI:10.1016/j.ijleo.2015.04.050

2. P. Senthil Kumar, S.S Dawn, C. Saipriya, A.V Samrot, Rasayan Journal of Chemistry, 11, 1686(2018), DOI:10.31788/RJC.2019.1225134 
RASĀYAN J. Chem.

Vol. 13 | No. 1 |188 - 194| January - March | 2020

3. V.Karthick, V. Ganesh Kumar, T. Stalin Dhas, G.Singaravelu, A. Mohamed Sadiq, K.Govindaraju Colloids and Surfaces B: Biointerfaces, 122, 505(2014), DOI:10.1016/j.colsurfb.2014.07.022

4. S.M. Ghoreishi, M. Behpour, M. Khayatkashani, Physica E: Low-dimensional Systems and Nanostructures, 44(1), 97(2011), DOI: 10.1016/j.physe.2011.07.008

5. A. Annamalai, S.T. Babu, N.A. Jose, D. Sudha, C.V. Lyza N. Anna Jose, S. Thomas, World Applied Sciences Journal, 13(8), 1833(2011),

6. J. Sarkar, S. Ray, D. Chattopadhyay, A. Laskar, K. Acharya, Bioprocess and Biosystems engineering, 35(4), 637(2012), DOI:10.1007/s00449-011-0646-4

7. A. Tripathy, A.M. Raichur, N. Chandrasekaran, Journal of Nanoparticle Research, 12, 237(2009), DOI: 10.1007/s11051-009-9602-5

8. V.Karthick, V.Ganesh Kumar, T.Maiyalagan, R. Deepa, K. Govindaraju, A. Rajeswari, T. Stalin Dhas Micro and Nanosystems, 4, 192(2012), DOI:10.2174/1876402911204030192

9. L. Guangquan, H. Dan, Q. Yongqing, G. Buyuan, G. Song, C. Yan, Y. Koji, W. Li, International Journal of Molecular Sciences, 13(1), 466(2012), DOI:10.3390/ijms13010466

10. T. Stalin Dhas, V. Ganesh Kumar, V.Karthick, K.Vasanth, G.Singaravelu, K.Govindaraju, Enzyme and Microbial Technology, 95, 100(2016), DOI:10.1016/j.enzmictec.2016.09.003

11. D.Roselin Jenifer, B.R.Yalathy, Rasayan Journal of Chemistry, 12, 630(2019), DOI: 10.31788/RJC.2019.1225134.

12. P.Raji, A.V. Samrot, D.B Rohan, P.D Kumar, R. Geetika, V.K Sharma, D. Keerthana, Rasayan Journal of Chemistry, 12,123(2019), DOI:10.31788/RJC.2019.1214054

13. H.O. Edeoga, D.E. Okwu, B.O. Mbaebie, African Journal of Biotechnology, 4(7), 685(2005), DOI: $10.5897 / \mathrm{AJB} 2005.000-3127$

14. R. Geetha, T. Ashokkumar, S. Tamilselvan, Cancer nanotechnology, 4(5), 91(2013), DOI: $10.1007 / \mathrm{s} 12645-013-0040-9$

15. T. Ashokkumar, D. Prabhu, R. Geetha, Colloids and Surfaces B: Biointerfaces, 123, 549(2014), DOI:10.1016/j.colsurfb.2014.09.051

16. X. Zhang, Y. Qu, W, Shen, J. Wang, H. Li, Z. Zhang, S. Li, J. Zhou, Colloids and Surfaces A: Physicochemical and Engineering Aspects, 497, 280(2016), DOI:10.1016/j.colsurfa.2016.02.033

17. V.D. Kulkarni and P.S. Kulkarni . International Journal of Chemical Studies, 1(3), 1(2013)

18. S. Honary, H. Barabadi, E. Gharaei, N. Farzaneh, Tropical Journal of Pharmaceutical Research, 12(1), 7(2013), DOI:10.4314/tjpr.v12i1.2

19. S.M. Nejad, S.G. Bonjar, N. Khaleghi, Nanomedicine Journal, 2(2), 153(2015), DOI: 10.7508/NMJ.2015.02.007

20. T. Elavazhagan and K.D. Arunachalam, International Journal of Nanomedicine, 6, 1265(2011), DOI: 10.2147/IJN.S18347.

21. R.D. Pasca, A. Mocanu, S.C. Cobzac, I. Petean, O. Horovitz, M.T. Cotisel, Particulate Science and Technology, 32(2), 131(2014), DOI:10.1080/02726351.2013.839589

22. D. Motlhanka, P. Houghton, A. Miljkovic-Brake, S. Habtemariam, African Journal of Pharmacy and Pharmacology, 4(8), 549(2010)

23. D. Motlhanka, P. Houghton, A. M Brake S. Habtemariam African Journal of Pharmacy and Pharmacology, 4, 549(2010).

[RJC-5515/2019] 